\title{
Tremor Differentiation on Surface Electromyography
}

\author{
Dr. Man Mohan Mehndiratta, MD, $\mathrm{DM}^{1}$, Dr. Munish Kumar, $\mathrm{MD}^{2}$ \\ Dr. Sanjay Pandey, MD, DM ${ }^{3}$. \\ ${ }^{I}$ Director, Professor And Head of Department, Department of Neurology, Janakpuri Superspeciality Hospital. \\ Janakpuri, New Delhi, India. \\ ${ }^{2}$ Senior Resident, Department of Neurology, Room No. - 511, GB Pant Postgraduate Institute of Medical \\ Education and Research, New Delhi, India \\ ${ }^{3}$ Professor, Department of Neurology, Chief, Parkinson Disease And Movement Disorder Room No. 507, \\ GB Pant Postgraduate Institute of Medical Education And Research, New Delhi, India
}

\begin{abstract}
Objective: The aim of this study was to differentiate tremors on the basis of the electromyographic examination. Methods: A total of 100 patients, having different kind of tremors were prospectively analyzed. A detailed neurological and electromyographic examination was performed. The tremor was studied in all limbs positions. Clinically, patients were divided into seven diagnostic groups fulfilling the respective diagnostic criteria; Parkinson's disease $(n=45)$, Essential tremor $(n=33)$, Psychogenic tremor $(n=07)$, Valproate induced tremor $(n$ $=07)$, Cerebellar tremor $(n=03)$, Primary writing tremor $(n=03)$ and Rubral tremor $(n=02)$.

Results: On surface electromyography tremors were divided into two groups: with synchronous and alternating pattern in the antagonist muscles. Tremor frequency may be useful for differentiation of low (less than $4 \mathrm{~Hz}$ ) frequency tremors (Rubral tremor) and high (more than $9 \mathrm{~Hz}$ ) frequency tremors (Valproate induced tremor) but not useful for tremors falling in middle frequency range $(4-9 \mathrm{~Hz})$ i.e Essential, PD, Cerebellar, Psychogenic and Primary writing tremors. Tremor amplitude is much variable and is not useful in tremor differentiation. Tremor burst pattern is also not useful as both synchronous and alternate pattern can be seen in a particular type of syndromic diagnosis. Tremor burst duration is a more reliable parameter for tremor differentiation.
\end{abstract}

Conclusion: If the electromyographic tremor examination is used in addition to the clinical criteria for tremor differentiation there will be no significant difficulties for tremor differentiation.

\section{Introduction}

Tremor is the most common movement. ${ }^{1}$ There are a number of different types of tremors, which are often confused with one another. Although most often the essential tremor is misdiagnosed with the Parkinsonian tremor, differentiation of other tremors on clinical grounds is also difficult. ${ }^{2}$ The tremor frequency, amplitude, burst duration and burst pattern are evaluated by surface electromyographic examination. On the basis of these parameters, various types of tremor can be differentiated. All tremors can be subdivided into two major groups according to the pattern of muscle activation, either synchronous or alternating in the antagonistic muscles. ${ }^{3-5}$

The tremor amplitude is variable and is not specific for different types of tremor and thus its diagnostic value is limited whereas tremor frequency is a more constant parameter. ${ }^{6}$ The tremors may be subdivided into low frequency (below $4 \mathrm{~Hz})$, middle frequency $(4-9 \mathrm{~Hz})$ and high frequency (above $9 \mathrm{~Hz})$ tremors. ${ }^{5}$

\section{Design/ Methods}

A total of 100 patients, more than 12 years of age, having different kind of tremors that presented to a tertiary care hospital in New Delhi, India between April 2012 to September 2013 were prospectively analyzed for clinical details and functional performance tests. This study was carried after ethical clearance and permission of the institute. A written informed consent was taken from subjects (parents in case of a minor), after adequate explanation. All patients were subjected to general physical and detailed neurological examination. Clinically, patients were divided into seven diagnostic groups fulfilling the respective diagnostic criteria; Parkinson's disease $(\mathrm{PD})^{7}(\mathrm{n}=45)$, Essential tremor $(\mathrm{ET})^{8}(\mathrm{n}=33)$, Psychogenic tremor $^{9}(\mathrm{n}=07)$, Valproate induced tremor $(\mathrm{n}=07$, those patients in which the tremor developed after the initiation of sodium valproate monotherapy), Cerebellar $\operatorname{tremor}^{8}(\mathrm{n}=03)$, Primary writing tremor ${ }^{8}(\mathrm{n}=03)$ and Rubral $\operatorname{tremor}^{8}(\mathrm{n}=02)$. Surface EMG was done on each patient using standard technique on Medelec / Teca Premier Plus EMG machine. Parameters of Surface EMG were set for optimum record of tremor. For this the sensitivity ranged from 50 to $500 \mu \mathrm{v}$, sweep speed ranged from 1 to 3 seconds, low frequency filter cutoff set at $10 \mathrm{~Hz}$ and a high frequency cutoff of $10 \mathrm{KHz}$. For each patient surface EMG of tremors was recorded in the involved limb in different positions (according to the phenomenology of tremor): rest - limbs fully supported against gravity, postural- outstretched horizontal prone position, during the writing and during target oriented movements like finger-nose or heel-shin testing. Patients were asked not to take 
alcohol the previous evening and caffeine beverages or tea in the morning of the examination. The ongoing drugs were stopped 24 hours before the day of recording. The examination was performed in a quiet room after allowing enough time for the patients to become familiar with the surroundings. Tremor activity was recorded on two channels by using two pairs of $10 \mathrm{~mm}$ silver-silver chloride electrodes from at least two antagonistic groups of muscles. Alcohol was applied to clean the skin before placing the electrodes. The electrodes were applied approximately $2 \mathrm{~cm}$ apart on the most prominent part of the muscle (belly) using conductive electrolyte gel. A reference electrode was placed above the elbow/ knee. The antagonistic muscles chosen were - in upper limb flexor carpi ulnaris and extensor carpi radialis or first dorsal interosseus muscle and second Palmar interosseus, in lower limb tibialis anterior and gastrocnemius. For each recording the tremor frequency $(\mathrm{Hz})$, mean amplitude (microvolts), mean burst duration (milliseconds) and burst pattern (synchronous or alternating) were assessed. The amplitude was measured peak-to-peak for each burst and the mean value was considered. The burst duration was measured for each burst and the mean value was determined. The mean tremor frequency and the activation pattern were assessed by visual inspection of the records. The tremor frequency was assessed by counting the number of tremor bursts per minute. Burst pattern were grouped into either synchronous (if tremor bursts in antagonistic muscles appear simultaneously) or alternating (if tremor bursts in antagonistic muscles appear alternately).

\section{Data analysis}

Demographic data and surface electromyographic parameters were recorded and analyzed using SPSS v20. 0 software. Values were expressed as mean \pm Standard deviation (SD) or mean \pm Standard error (SE). Oneway ANOVA with post hoc Newman-Keuls analysis were used to compare the data from the electromyographic examination. The Pearson's chi-square test and Student's t-test was used in univariate analysis for calculating the $\mathrm{p}$-value. The differences were considered significant when the $\mathrm{P}$ value was less than 0.05 . The Spearman rank correlation coefficient $(\mathrm{r})$ was used to analyze the relationship between tremor frequency and burst duration. The correlation coefficient $(r)$ considered as poor if $r<0.3$ and moderate if $0.3<r<0.5$ and strong if $r>0.5$.

\section{Results}

Out of hundred patients, 69 were males (M: F ratio=2. 22:1). Their mean \pm SD age was $48.91 \pm 18.2$ years (range 13-91 years). Forty-five patients had PD tremor, mean \pm SD age was $54.48 \pm 13.39$ years (range $13-75$ years) with male: female ratio was $1.65: 1$ and mean disease duration was 3.45 years.

Thirty-three patients had ET, the mean \pm SD age was $51.51 \pm 19.04$ years (range 15 to 91 years) with male: female ratio was $10: 1$, out of which five $(15.15 \%)$ had positive family history. Their mean disease duration was 3.93 years.

Among other diagnostic groups, seven patients with Psychogenic tremor (5 clinically definite, 2 probable) having a symptom duration 6 months to 6 years (mean 20 months) and obvious stressors, four males and three females with mean \pm SD age $37.28 \pm 17.71$ years. The tremor was present in all limb positions. Seven patients (two males and five females) with epilepsy on monotherapy with valproate (duration of treatment was 6 months to 2 years, mean duration of treatment was 0.93 years, mean \pm SD dose of valproate was $1500 \pm 500 \mathrm{mg}$ daily) developed tremor and all had postural type of tremor only. The mean \pm SD age was $24.28 \pm 7.45$ years. Three patients had cerebellar tremor, one male and two female with mean \pm SD age $31.0 \pm 16.7$ ears, the tremor was present in all limb positions except at rest. Three male patients had a Primary writing tremor involving dominant hand at the time of writing with mean \pm SD age $60.33 \pm 14.01$ years and mean disease duration was 3.17 years. Two patients of rubral tremor, both post-operated cases of hypothalamic hamartoma, one male and one female with a mean \pm SD age was $17.0 \pm 5.65$ years and tremor was present in all limb positions.

According to the surface electromyographic examination bursts of EMG activity separated by relative silence (inter-burst interval) were noted in all types of tremor and patients were divided into two groups: either with synchronous pattern $(65 \%)$ or with alternating pattern $(35 \%)$ in the antagonist muscles. (Figure 1 and 2 ) According to frequency of tremor, low frequency (less than $4 \mathrm{~Hz}$ ) include rubral tremor, middle frequency $(4-9$ $\mathrm{Hz}$ ) includes ET, PD, cerebellar, psychogenic, primary writing tremor and high frequency (above $9 \mathrm{~Hz}$ ) includes valproate induced tremor.

\section{Tremors with synchronous pattern (Table 1)-}

This group includes ET type I (with synchronous activity), PD tremor type I (with synchronous activity), cerebellar tremor, primary writing tremor, and valproate induced tremor. The ET at rest showed a lower frequency $(\mathrm{P}<0.05)$ as compared to postural tremor whereas the PD tremor at rest had comparable frequency and amplitude $(\mathrm{P}>0.05)$ but longer burst duration $(\mathrm{P}<0.05)$ as compared to postural tremor. At rest, the ET frequency was $1.5 \mathrm{~Hz}$ or more lower with respect to the postural type $(\mathrm{P}<0.05)$. The $\mathrm{PD}$ tremor had longer burst duration $(\mathrm{P}<0.05)$ as compared to ET both at rest and on posture. The cerebellar tremor can be differentiated from ET type I and PD tremor type I on the basis of its longer burst duration $(\mathrm{P}<0.05)$ and had smallest amplitude among other synchronous tremors $(\mathrm{P}<0.05)$. The primary writing tremor had statistically significant lower frequency and 
longer burst duration $(\mathrm{P}<0.05)$ as compared to ET. The valproate induced postural tremor had smaller amplitude as compared to postural ET $(\mathrm{P}<0.05)$ and had higher frequency $(\mathrm{P}<0.05)$, smaller amplitude $(\mathrm{P}<0.05)$ and shorter burst duration $(\mathrm{P}<0.05)$ as compared to postural $\mathrm{PD}$ tremor.

\section{Tremors with alternating pattern (Table 2) -}

Tremors with alternating pattern includes ET type II (with alternating activity), PD tremor type II (with alternating activity), rubral and psychogenic tremor. Both ET type II and PD tremor type II electromyographically resemble their respective type I tremor except for their burst pattern. Rubral tremor had same mean frequency of $3.50 \pm 0.70 \mathrm{~Hz}$ (range $3-4 \mathrm{~Hz}$ ) in all limb positions but variable amplitude and burst duration. Rubral tremor had lowest frequency $(\mathrm{P}<0.05)$ and the longest burst duration $(\mathrm{P}<0.05)$ as compared to the other alternating tremors. Psychogenic tremor had the highest frequency and shortest burst duration as compared to the other alternating tremors $(\mathrm{P}<0.05)$.

\section{Discussion}

Our results confirmed previous suggestions that all tremors can be subdivided into two main groups; tremor with synchronous pattern and tremor with alternating pattern. ${ }^{4,5}, 9-11$ The finding that on surface electromyography all types of tremor had bursts of EMG activity separated by relative silence (inter-burst interval) which is similar to previous studies. The burst pattern on SEMG (either synchronous or alternating) remains the same in different positions of recording for a particular type of tremor. After assigning, the tremor to one of the groups (with synchronous or alternating activity), the tremor frequency, burst duration and amplitude may further help in the differentiation of tremors. We found that ET had both synchronous (Type I, $72.7 \%$ of patients) and alternating (Type II, $27.3 \%$ of patients) activity. A study evaluating surface EMG patterns in ET found synchronous activity in 59\% cases and alternating activity in $41 \%$ of cases. ${ }^{12}$ In a study on 146 Chinese patients having ET, the SEMG finding revealed two patterns, one of the synchronous type (73\%) and the other of alternating type (27\%). ${ }^{13}$ Synchronous EMG found in $68 \%$ in ET. ${ }^{14}$ In contradiction to most of the previous studies, we found that PD tremor also had both synchronous (Type I, $62.2 \%$ of patients) and alternating (Type II, $37.8 \%$ of patients) pattern, so it is very difficult to differentiate ET and PD tremors. on the basis of their burst patterns. In a study by Gironell $\mathrm{A}$ et al, among 29 patients with PD tremor, $85 \%$ had synchronous pattern on SEMG. ${ }^{15}$ Another study by Milanov I evaluated rest and postural tremor in 110 patients with Parkinson's disease. Rest tremor was characterized by alternating EMG activity in all patients, but this was not the case with postural tremor, for which some patients had synchronous activity while others had alternating activity.

We found clinical and electrophysiological similarities between ET and PD tremor, as both had similar tremor frequency range of 4-8 Hz, similar burst pattern on SEMG, overlapping resting tremors (a typical PD tremor) and postural tremors (mainly in ET patients). This suggests an association between ET and PD. Various other studies also found similar association. ${ }^{17-19}$ All patients with cerebellar, primary writing and valproate induced tremor had synchronous pattern whereas rubral and psychogenic tremor had alternating pattern. Our findings are similar to previous studies. ${ }^{3,5,10,14,20-22}$ There is great variation in amplitude and burst duration but the frequency is the most constant parameter. ${ }^{21,}{ }^{22}$ However, the frequency ranges of different tremors overlap. ${ }^{4,23}$ Our findings suggest that the frequency may be useful for differentiation of low (less than $4 \mathrm{~Hz}$ ) frequency tremors (rubral tremor) and high (more than $9 \mathrm{~Hz}$ ) frequency tremors (valproate induced tremor). Tremors falling in middle frequency range $(4-9 \mathrm{~Hz})$ i.e ET, PD tremor, cerebellar, psychogenic and primary writing tremors, can be differentiated on other SEMG parameters. Parkinsonian tremor is in the lower part of the middle frequencies (5-6 $\mathrm{Hz}$ ), while the ET is in the upper part $(7-8 \mathrm{~Hz})$. However, it is not possible to differentiate both tremors only on frequency basis $(\mathrm{P}>0.05)$. Both can be differentiated on the basis of their burst durations which is statistically significant $(\mathrm{P}<0.05)$. Essential tremor usually had burst duration $<100 \mathrm{msec}$ whereas PD tremor had $>100$ msec. This finding was similar to study by Milanov I. ${ }^{5}$ The rest and postural ET type I and II had comparable amplitude and burst duration ( $\mathrm{P}>0.05)$, but can be differentiated on the basis of their frequencies as postural essential tremor had greater frequency (mean $8.28 \pm 2.49 \mathrm{~Hz}$ ) as compared to rest tremor (mean $4.83 \pm 1.04 \mathrm{~Hz})(\mathrm{P}$ $<0.05$ ). This qualifies the neurophysiological criteria for essential tremor introduced by Deuschl $\mathrm{G}$ et al., ${ }^{11}$ which says that the tremor frequency greater than or equal to $4 \mathrm{~Hz}$ and rest tremor absent or, if present, frequency $1.5 \mathrm{~Hz}$ lower with respect to the postural tremor. Gironell A et al ${ }^{15}$ in a study found that the diagnostic value of the neurophysiologic criteria applied for the diagnosis of essential tremor showed a sensitivity of $97.7 \%$, specificity of $82.3 \%$, a positive predictive value of $95.1 \%$, a negative predictive value of $91.1 \%$. Their burst duration was short $(50-100 \mathrm{msec})$ and the amplitude was more than $100 \mu \mathrm{v}$. The differentiation between cerebellar and ET type I, being both of synchronous pattern, is not difficult due to the lower frequency $(\mathrm{P}<0.05)$ and long burst duration $(\mathrm{P}$ $<0.05$ ) of cerebellar tremor. Findings are similar to study by Saeed $\mathrm{S}$ et al. ${ }^{10}$ In contradiction to our finding, a study by Milanov I ${ }^{5}$ found that cerebellar tremor had higher frequency but short burst duration as compared to ET. Cerebellar tremor can be differentiated from PD tremor type I by having longer burst duration $(\mathrm{P}<0.05)$. Cerebellar tremor had smallest amplitude among other simultaneous tremor $(\mathrm{P}<0.05)$. Primary writing tremor had 
higher amplitude $(\mathrm{P}<0.05)$ whereas valproate induced tremor had greater frequency $(\mathrm{P}<0.05)$ and shorter burst duration $(\mathrm{P}<0.05)$ as compared to cerebellar tremor. Clinically the valproate induced tremor resemble ET ${ }^{20}$ and had a comparable frequency $(\mathrm{P}>0.05)$ with it, but can be differentiated by having a statistically significant smaller amplitude $(\mathrm{P}<0.05)$. The valproate induced tremor can be differentiated from the PD postural tremor by having higher frequency $(\mathrm{P}<0.05)$, smaller amplitude $(\mathrm{P}<0.05)$ and shorter burst duration $(\mathrm{P}<0.05)$. It is very difficult to differentiate primary writing tremor and essential tremor clinically, but on SEMG the Primary writing tremor had lower frequency $(\mathrm{P}<0.05)$ and longer burst duration $(\mathrm{P}<0.05)$ as compared to ET. PD tremor type I had a comparable frequency, amplitude and burst duration $(\mathrm{P}>0.05)$. Comparative study between primary writing tremor and other tremors has not been reported previously.

Rubral tremor had same mean frequency of $3.50 \pm 0.70 \mathrm{~Hz}$ (range $3-4 \mathrm{~Hz}$ ) in all limb positions. It had the smallest frequency $(\mathrm{P}<0.05)$ and the longest burst duration $(\mathrm{P}<0.05)$ as compared to the other alternating tremors. Similar to results by Milanov I. ${ }^{5}$ The lower frequency and longer burst duration of rubral tremor can differentiate it from ET type II, PD type II and psychogenic tremor.

Psychogenic tremor had a mean frequency of $8.14 \pm 1.08 \mathrm{~Hz}($ range $5-14 \mathrm{~Hz}$ ) and mean burst duration of $58.56 \pm$ 4.77 milliseconds. It had the highest frequency $(\mathrm{P}<0.05)$ and the shortest burst duration as compared to the other alternating tremors $(\mathrm{P}<0.05)$. In contradiction to study by Milanov $\mathrm{I}$, we found that the higher frequency and shorter burst duration can differentiate Psychogenic tremor from other alternating tremors. A study found the frequency of $5.6 \pm 1.5 \mathrm{~Hz}$ in psychogenic tremor. ${ }^{14}$

\section{Conclusion}

Tremor can be differentiated on the surface electromyography parameters. Tremor frequency may be useful for differentiation of low (less than $4 \mathrm{~Hz}$ ) frequency tremors (Rubral tremor) and high (more than $9 \mathrm{~Hz}$ ) frequency tremors (Valproate induced tremor) but not useful for tremors falling in middle frequency range $(4-9$ $\mathrm{Hz}$ ) i.e Essential, PD, Cerebellar, Psychogenic and Primary writing tremors. Tremor amplitude is much variable and is not useful in tremor differentiation. Tremor burst pattern is also not useful as both synchronous and alternate pattern can be seen in a particular type of syndromic diagnosis. Tremor burst duration is a more reliable parameter for tremor differentiation. If the electromyographic tremor examination is used in addition to the clinical criteria for tremor differentiation there will be no significant difficulties for tremor differentiation.

\section{References}

[1]. Britton TC. Essential tremor and its variants. Curr Opin Neurol 1995;8:314 \pm 319

[2]. Rajput AH. Pathological and neurochemical basis of essential tremor. In:Findley LJ, Koller WC, editors. Handbook of tremor disorders,

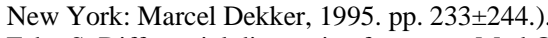

[3]. Fahn S. Differential diagnosis of tremors. Med Clin North Am 1972;56:1363-75.

[4]. Findley LJ, Cleeves L. Classification of Tremor. In: Disorders of Movement: Clinical, Pharmacological and physiological aspects. Academic Press 1989:505-19.

[5]. Milanov I. Electromyographic differentiation of tremors. J Clin Neurophysiol 2001;112: 1626-32.

[6]. Gresty M, Buckwell D. Spectral analysis of tremor: understanding the results. J Neurol Neurosurg Psychiatry 1990;53:976-81.).

[7]. Hughes AJ, Daniel SE, Kilford L, Lees AJ. Accuracy of clinical diagnosis of idiopathic Parkinson's disease: a clinico-pathological study of 100 cases. J Neurol Neurosurg Psychiatry 1992;55:181-4.

[8]. Deuschl G, Bain P, Brim M. Consensus statement of the Movement Disorder Society on Tremor. Ad Hoc Scientific Committee. Mov Disord 1998;13(3):2-23.

[9]. Fahn S, Williams PJ. Psychogenic dystonia. Adv Neurol 1988;50:431-55.

[10]. Saeed S, Hassanein A, Nada M, Azmy R. Neurophysiological assessment of major types of tremor: Clinical and electrophysiological study. Egypt J. Neurol. Psychiat. Neurosurg 2004;41(1):213-20.

[11]. Deuschl G, Krack P, Lauk M, Timmer J. Clinical Neurophysiology of tremor. J Clin Neurophysiol 1996;13:110 -21.

[12]. Milanov I. Clinical and electromyographic examinations of patients with essential tremor. Can J Neurol Sci 2000;27(1):65-70.

[13]. Hsu YD, Chang MK, Sung SC, Hsein HH, Deng JC. Essential tremor: clinical, electromyographical and pharmacological studies in 146 Chinese patients. Chinese Med J 1990;45:93-9.

[14]. Gironell A, Kulisevsky J, Barbanoj M, Gich I, Pascual-Sedano B, Otermín P. Postural tremor: clinical and neurophysiological study in a consecutive series of 300 patients. Med Clin (Barc) 2001;117(16):601-5.

[15]. Gironell A, Kulisevsky J, Pascual-Sedan B, and Barbanoj M. Routine Neurophysiologic Tremor Analysis as a Diagnostic Tool for Essential Tremor: A Prospective Study. J Clin Neurophysiol 2004;21:446-50.

[16]. Milanov I. Clinical and electromyographic examinations of Parkinsonian tremor. Parkinsonism Relat. Disord 2000;6(4):229-35.

[17]. Louis E.D, Frucht S.J. Prevalence of essential tremor in patients with parkinson's disease vs parkinson-plus syndromes. Mov.Disord 2007;22:1402-7.

[18]. Zorzon M, Capus L, Pellegrino A, Cazzato G, Zivadinov R. Familial and environmental risk factors in parkinson's disease: a casecontrol study in north-east italy. Acta Neurol. Scand 2002;105:77-82.

[19]. Tan EK, Lee SS, Fook-Chong S, Lum SY. Evidence of increased odds of essential tremor in parkinson's disease. Mov.Disord 2008;23:993-7.

[20]. Mehndiratta MM, Satyawani M, Gupta S, Khwaja GA. Clinical and surface EMG characteristics of valproate induced tremors. Electromyogr clin. Neurophysiol 2005; 45:177-82.

[21]. Cleeves L, Findley LJ. Amplitude fluctuations in essential tremor: implications for clinical trials. Motor disturbances. London: Academic Press 1987;1:41-6.

[22]. Freund HJ, Honberg V, Hefter H. Clinical aspects and treatment. In: Benecke R, Conrad B, Marsden CD, editors. Motor disturbances. London: Academic Press 1987;1:19-40. 
[23]. Deuschl G, Zimmermann R, Gender H, Lucking CH. Physiological classification of essential tremor. In: Findley LJ, Koller WC, editors. Handbook of tremor disorders, New York: Marcel Dekker 1995;195-208.

Figure 1. A record of surface electromyogram with synchronous pattern (recording from flexor carpi ulnaris and extensor carpi radialis)

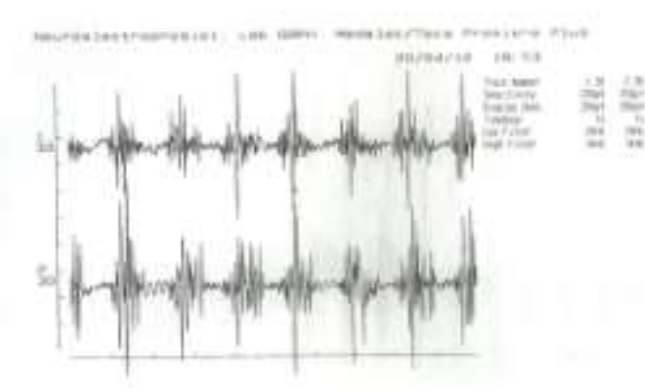

Figure 2. A record of surface electromyogram with alternating pattern (recording from flexor carpi ulnaris and extensor carpi radialis)

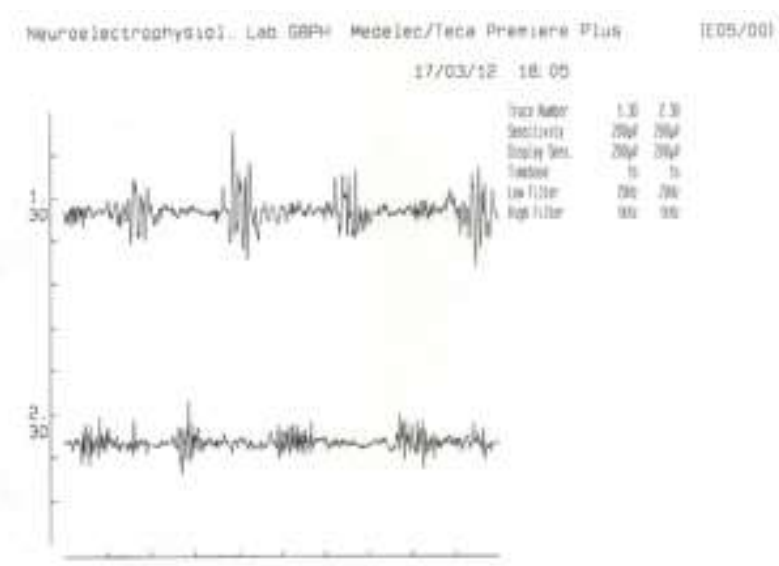


Table 1. SEMG parameters of Tremors with synchronous pattern.

\begin{tabular}{|c|c|c|c|c|c|c|c|c|c|c|c|c|c|}
\hline \multicolumn{14}{|c|}{ Tremors with synchronous pattern } \\
\hline \multirow[t]{2}{*}{ Diagnosis } & \multirow[t]{2}{*}{$\mathbf{n}$} & \multicolumn{3}{|c|}{ SEMG at rest } & \multicolumn{3}{|c|}{ SEMG on action } & \multicolumn{3}{|c|}{ SEMG on intention } & \multicolumn{3}{|c|}{ SEMG task specific } \\
\hline & & 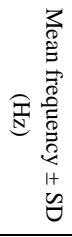 & 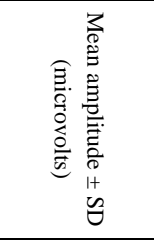 & 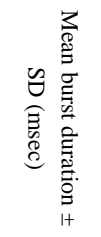 & 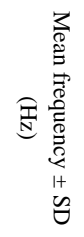 & 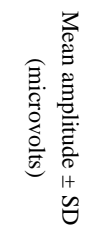 & 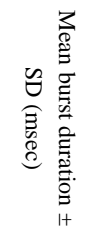 & 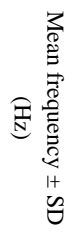 & 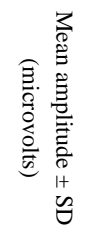 & 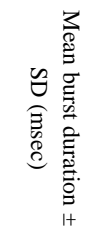 & 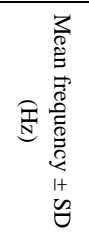 & 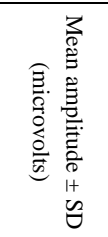 & 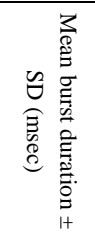 \\
\hline $\begin{array}{l}\text { Essential } \\
\text { tremor type I }\end{array}$ & 24 & $\begin{array}{c}5.00 \pm \\
1.41\end{array}$ & $188.75 \pm 67.25$ & $\begin{array}{l}74.36 \pm \\
20.40\end{array}$ & $\begin{array}{r}8.40 \pm \\
2.72\end{array}$ & $\begin{array}{c}247.04 \pm \\
37.54\end{array}$ & $\begin{array}{c}86.56 \pm \\
32.88\end{array}$ & & & & & & \\
\hline $\begin{array}{l}\text { Parkinsonian } \\
\text { tremor type I }\end{array}$ & 28 & $\begin{array}{c}5.45 \pm \\
1.05\end{array}$ & $\begin{array}{c}224.34 \pm \\
24.02\end{array}$ & $\begin{array}{c}118.98 \pm \\
6.17\end{array}$ & $\begin{array}{c}5.60 \pm \\
1.34\end{array}$ & $\begin{array}{c}206.92 \pm \\
19.27\end{array}$ & $\begin{array}{c}109.93 \pm \\
5.83\end{array}$ & & & & & & \\
\hline $\begin{array}{l}\text { Cerebellar } \\
\text { tremor }\end{array}$ & 03 & & & & 4.00 & 70.25 & 165.72 & $\begin{array}{l}5.67 \pm \\
1.53\end{array}$ & $\begin{array}{l}84.75 \pm \\
13.57\end{array}$ & $\begin{array}{c}123.89 \pm \\
35.81\end{array}$ & & & \\
\hline $\begin{array}{l}\text { Primary } \\
\text { writing } \\
\text { tremor }\end{array}$ & 03 & & & & 7.00 & 312.50 & 126.29 & & & & $\begin{array}{c}5.67 \pm \\
1.53\end{array}$ & $\begin{array}{c}463.67 \pm \\
228.97\end{array}$ & $\begin{array}{c}118.47 \pm \\
8.22\end{array}$ \\
\hline $\begin{array}{l}\text { Valproate } \\
\text { induced } \\
\text { tremor }\end{array}$ & 07 & & & & $\begin{array}{c}9.57 \pm \\
0.94\end{array}$ & $\begin{array}{c}113.96 \pm \\
21.44\end{array}$ & $\begin{array}{c}65.09 \pm \\
9.86\end{array}$ & & & & & & \\
\hline Total & 65 & & & & & & & & & & & & \\
\hline
\end{tabular}


Table 2. SEMG parameters of Tremors with alternating pattern.

\begin{tabular}{|c|c|c|c|c|c|c|c|c|c|c|}
\hline \multicolumn{11}{|c|}{ Tremors with alternating pattern } \\
\hline \multirow{2}{*}{ Diagnosis } & \multirow[t]{2}{*}{ n } & \multicolumn{3}{|c|}{ SEMG at rest } & \multicolumn{3}{|c|}{ SEMG on action } & \multicolumn{3}{|c|}{ SEMG on intention } \\
\hline & & 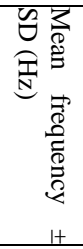 & 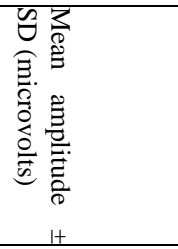 & 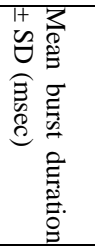 & 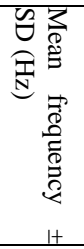 & 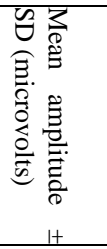 & 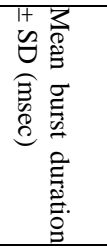 & 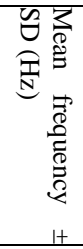 & 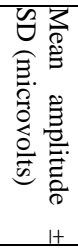 & 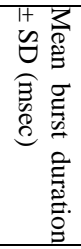 \\
\hline $\begin{array}{l}\text { Essential tremor type } \\
\text { II }\end{array}$ & 09 & $\begin{array}{l}5.00 \pm \\
1.41\end{array}$ & $188.75 \pm 67.25$ & $\begin{array}{l}74.36 \pm \\
20.40\end{array}$ & $\begin{array}{l}8.40 \pm \\
2.72\end{array}$ & $\begin{array}{c}247.04 \\
\pm \\
37.54\end{array}$ & $\begin{array}{l}86.56 \pm \\
32.88\end{array}$ & & & \\
\hline $\begin{array}{ll}\text { Parkinsonian } & \text { tremor } \\
\text { type II } & \end{array}$ & 17 & $\begin{array}{l}5.45 \pm \\
1.05\end{array}$ & $\begin{array}{l}224.34 \pm \\
24.02\end{array}$ & $\begin{array}{l}118.98 \\
\pm \\
6.17\end{array}$ & $\begin{array}{l}5.60 \pm \\
1.34\end{array}$ & $\begin{array}{l}206.92 \pm \\
19.27\end{array}$ & $\begin{array}{l}109.93 \pm \\
5.83\end{array}$ & & & \\
\hline Rubral tremor & 02 & $\begin{array}{l}3.50 \\
\pm 0.70\end{array}$ & $\begin{array}{l}242.25 \pm \\
24.39\end{array}$ & $\begin{array}{l}145.3 \\
9 \pm \\
17.83\end{array}$ & $\begin{array}{l}3.50 \pm \\
0.70\end{array}$ & $\begin{array}{l}437.25 \\
\pm \\
105.71\end{array}$ & $\begin{array}{l}160.63 \\
\pm \\
1.69\end{array}$ & $\begin{array}{l}3.50 \\
\pm \\
0.70\end{array}$ & $\begin{array}{l}435 . \\
00 \pm \\
102 . \\
53\end{array}$ & $\begin{array}{l}160 . \\
17 \pm \\
1.65\end{array}$ \\
\hline Psychogenic tremor & 07 & 7.00 & 336.00 & 49.70 & $\begin{array}{l}8.14 \\
\pm \\
1.08\end{array}$ & $\begin{array}{l}162.93 \\
\pm \\
33.54\end{array}$ & $\begin{array}{l}58.56 \pm \\
4.77\end{array}$ & 7.00 & $\begin{array}{l}105 . \\
50\end{array}$ & $\begin{array}{l}60.9 \\
9\end{array}$ \\
\hline Total & 35 & & & & & & & & & \\
\hline
\end{tabular}

